\title{
Impact of Physical Training on Sex Hormones and Their Receptors During $N$-Methyl- $N$-nitrosourea- induced Carcinogenesis in Rats
}

\author{
IWONA MALICKA ${ }^{1}$, KATARZYNA SIEWIERSKA ${ }^{1}$, CHRISTOPHER KOBIERZYCKI ${ }^{2}$, JEDRZEJ GRZEGRZOLKA ${ }^{2}$, \\ ALEKSANDRA PIOTROWSKA ${ }^{2}$, URSZULA PASLAWSKA ${ }^{3}$, MAREK CEGIELSKI ${ }^{2}$, PIOTR DZIEGIEL ${ }^{1,2}$, \\ MARZENNA PODHORSKA-OKOLOW ${ }^{2}$ and MAREK WOZNIEWSKI ${ }^{1}$ \\ ${ }^{1}$ Department of Physiotherapy, University School of Physical Education, Wroclaw, Poland; \\ ${ }^{2}$ Department of Histology and Embryology, Wroclaw Medical University, Wroclaw, Poland; \\ ${ }^{3}$ Department of Internal Medicine and Clinic of Diseases of Horses, Dogs, and Cats, \\ University of Environmental and Life Sciences, Wroclaw, Poland
}

\begin{abstract}
Background/Aim: The risk of breast cancer is related to duration of exposure to sex hormones, especially estrogen. The aim of this study was to assess the impact of physical training $(P T)$ on estrogen and progesterone levels and expression of their receptors during carcinogenesis induced by $N$-methyl-N-nitrosourea $(M N U)$ in rats. Materials and Methods: Fifty female Sprague-Dawley rats were intraperitoneally administered MNU and divided into four groups: low-, moderate-, and high-intensity PT, and no PT (control). Plasma levels of sex hormones and tissue expression of their receptors were quantified and statistically analyzed. Results: In the group of rats subjected to PT, a significantly higher progesterone level was observed. The highest progesterone level was noted in the low-intensity PT group. An increase in apoptosis of $M N U$-induced tumor cells was also demonstrated in the PT groups. Conclusion: PT stimulates apoptosis of tumor cells without an increase in their proliferative activity. The increase in apoptosis of tumor cells correlates positively with the progesterone level.
\end{abstract}

Breast cancer is the most common type of malignant neoplasm in women, with approximately 1.5 million new cases diagnosed annually worldwide (1). The risk of its occurrence

This article is freely accessible online.

Correspondence to: Iwona Malicka, Ph.D., Associate Professor, Department of Physiotherapy, University School of Physical Education, Al. I. J. Paderewskiego 35, 51-612 Wroclaw, Poland. Tel: +48 713473519, Fax: +48 713473081, e-mail: iwona.malicka@awf.wroc.pl

Key Words: Breast cancer, physical training, $N$-methyl- $N$-nitrosourea, progesterone, estrogen. increases with age, reaching the highest incidence, at approximately $12 \%$, in the postmenopausal period. In regard to the different risk factors associated with breast cancer risk, exposure to sex hormones, namely estrogen and progesterone, and the level of physical activity are often reported $(2,3)$. This is closely related to early menarche (before the age of 12 years) and late menopause (over the age of 55 years), as well the influence of physical activity on the levels of sex hormones and decrease of the number of ovulatory cycles $(4,5)$.

Estradiol, the primary estrogen, binds to estrogen receptor (ER)- $\alpha$ (higher affinity) and ER $\beta$. By interfering with $\mathrm{ER} \alpha$, estradiol stimulates proliferation and differentiation of mammary epithelial cells $(6,7)$. It is estimated that approximately $70-80 \%$ of breast cancers demonstrate ER expression (8). Likewise, progesterone acts on mammary epithelial cells synergistically with estrogens, stimulating their growth $(2,9)$. During physical training (PT), the levels of these hormones increase with increasing PT intensity. Single PT sessions increase blood estradiol and progesterone levels, whereas prolonged systematic PT reduces ovarian secretion, which results in a decrease in blood estradiol and progesterone levels (10). The significant relationship between the level of PT and risk of breast cancer has frequently been reported. However, there are no consistent results defining the relationship between PT and sex hormone levels (11-14), nor with the expression of their receptors (15-17).

Rats and mice are the main species in experimental studies of mammary gland tumors due to the fact that their glands they have the most similar structure and function to human glands (18). $N$-Methyl- $N$-nitrosourea (MNU), which is commonly used in these studies, is an agent recognized as causing tumor of the mammary gland $(19,20)$.

Therefore, the aim of this study was the assessment of the impact of PT on estrogen and progesterone levels and on the 
expression of ER and progesterone receptor (PR) during MNU-induced carcinogenesis in rats.

\section{Materials and Methods}

Animals. Fifty female Sprague-Dawley rats of 28 days of age, housed under stable living conditions at the Animal Research Facility of the Department of Pathomorphology, Wroclaw Medical University (constant temperature and humidity, 12/12 h light and dark cycle, rat chow and water ad libitum), were utilized in the experiment. The study was approved by the local Ethics Committee (decision no. 37/2010). Following a two-week quarantine period, animals were intraperitoneally injected with $180 \mathrm{mg} / \mathrm{kg}$ body weight of MNU (Sigma-Aldrich, Munich, Germany) (19). Four weeks after MNU administration, the animals were monitored in accordance with a previously applied procedure (21).

Physical training. The animals were divided into four groups: the sedentary control (SC; $n=14)$, and low- (LIT; $n=12)$, moderate(MIT; n=12) and high-intensity (HIT; n=12) PT groups. Immediately after MNU administration, all training rats (LIT, MIT, HIT) were subjected to supervised 12-week PT (5 days a week) on a 3-position treadmill (Exer 3/6; Columbus Instruments, Columbus, $\mathrm{OH}, \mathrm{USA})$. The speed of the treadmill and training duration were gradually increased (Table I). For the LIT group, the training parameters were reduced by $20 \%$ compared to the MIT group, whereas for the HIT group, they were increased by $20 \%$ (22). After the administration of $\mathrm{MNU}$, the rats from the SC group were not subjected to PT, however, they were housed for 12 weeks under the same conditions as training rats.

Tissue collection. Twelve weeks following MNU administration, the animals were sacrificed as previously described (20). All tumors detected by palpation were excised and measured. All tissues were fixed in $4 \%$ buffered formalin, dehydrated and embedded in paraffin. The blood was also collected for analysis at the post-mortem examination. The blood was centrifuged $\left(500 \times g\right.$ for $15 \mathrm{~min}$ at $\left.4^{\circ} \mathrm{C}\right)$ and the obtained plasma was frozen.

Histopathological evaluation. Hematoxylin and eosin-stained (HE) 6 - $\mu$ m-thick paraffin slides were prepared for histopathological verification, as previously described (21). In brief, two independent pathologists utilizing a double-headed BX41 microscope (Olympus, Tokyo, Japan) evaluated tumor sections as benign or malignant lesions based on the classification of rat mammary gland tumors according to Russo and Russo (23).

Tissue microarray (TMA) construction. Representative tumor areas were selected on HE-stained sections. TMAs were constructed using a Manual Tissue Arrayer I (Beecher Instruments Inc., Sun Prairie, WI, USA). Triplicate tissue cores $(2 \mathrm{~mm})$ with potentially the highest tumor cell content were obtained from non-necrotic areas in the tumor and transferred into the recipient paraffin block, as previously described (20).

Immunohistochemistry. All reactions were performed on 4- $\mu$ m-thick paraffin sections obtained from TMA blocks, using Autostainer Link48 (Dako, Glostrup, Denmark). Firstly, deparaffinization, rehydration and antigen retrieval were performed using EnVision FLEX Target Retrieval Solution $\left(97^{\circ} \mathrm{C}, 20 \mathrm{~min}\right.$; $\mathrm{pH} 6$ for Ki-67 and
Table I. Moderate-intensity physical training protocol.

\begin{tabular}{lcc}
\hline $\begin{array}{l}\text { Period of training } \\
\text { (week) }\end{array}$ & $\begin{array}{c}\text { Speed of treadmill } \\
(\mathrm{km} / \mathrm{h})\end{array}$ & $\begin{array}{c}\text { Duration } \\
(\text { minutes })\end{array}$ \\
\hline 1 & 0.60 & 10 \\
2 & 0.96 & 20 \\
3 & 1.20 & 30 \\
4 & 1.44 & 40 \\
5 & 1.68 & 50 \\
6 & 1.68 & 55 \\
7 & 1.68 & 60 \\
8 & 1.68 & 65 \\
$9-12$ & 1.68 & 30 \\
\hline
\end{tabular}

$\mathrm{pH} 9$ for $\mathrm{ER} \alpha$ and PR) in PT-Link (Dako). The activity of endogenous peroxidase was blocked by 5 -minute incubation with EnVision FLEX Peroxidase-Blocking Reagent (Dako). Monoclonal mouse anti-rat Ki67, clone MIB-5 (1:25, Dako), polyclonal rabbit anti-rat ER $\alpha$ (1:100; Novus Biologicals, Abingdon, United Kingdom) and polyclonal rabbit anti-rat PR (1:100; Novus) were used as the primary antibodies. The tested sections were incubated with primary antibodies for $20 \mathrm{~min}$ at room temperature (RT), followed by incubation with secondary goat antibodies coupled to a dextran core, conjugated with horseradish peroxidase (EnVision FLEX/HRP) for 20 min. 3,3'-Diaminobenzidine (DAB; Dako) was utilized as the peroxidase substrate and the slides were incubated for $10 \mathrm{~min}$. Finally, all sections were counterstained with EnVision FLEX Hematoxylin (Dako) for 5 minutes and closed with coverslips in Dako Mounting Medium (Dako). Sections were evaluated as described below.

Terminal deoxynucleotidyl transferase dUTP nick end labeling (TUNEL) method. The apoptosis assay was conducted using ApopTag in situ Apoptosis Detection Kit (Millipore, Billerica, MA, USA), as previously described (21). In brief, TMA sections were dewaxed in xylene, rehydrated in ethanol alcohol and rinsed in distilled water and phosphate-buffered saline (PBS). The sections were digested using Proteinase K (Dako) for $5 \mathrm{~min}$ at RT. The activity of endogenous peroxidase was blocked by 5 -min incubation in $3 \% \mathrm{H}_{2} \mathrm{O}_{2}$ in PBS. In the next step, the sections were incubated, first with Equilibration Buffer for $10 \mathrm{~min}$ at RT and then with TdT Enzyme and Reaction Buffer at $37^{\circ} \mathrm{C}$ for $1 \mathrm{~h}$. The reaction was stopped by incubation with Stop Buffer for $10 \mathrm{~min}$ at RT. Subsequently, the sections were incubated with anti-digoxigenin peroxidase-conjugated secondary antibodies and the substrate for peroxidase, DAB was applied for $10 \mathrm{~min}$ at RT. Finally, the sections were counterstained with Mayer's hematoxylin, dehydrated in ethanol alcohol and xylene and the preparations were mounted in SUB-X Mounting Medium (Dako). Sections were evaluated as described below.

Assessment of immunohistochemical reaction. The analysis was performed by two researchers utilizing a double-headed BX41 microscope combined with computer-aided image analysis software Cell^D (Olympus). The evaluation of the expressions of Ki-67 antigen, ER $\alpha, P R$ and TUNEL reaction in the TMA sections was based on the count of cancer cell nuclei with color reaction relative 
Table II. Body weight and amount of administered $N$-methyl-N-nitrosourea $(M N U)$ in the experimental groups.

\begin{tabular}{|c|c|c|c|c|c|c|c|}
\hline Variable & $\mathrm{SC}(\mathrm{n}=9)$ & $\operatorname{LIT}(\mathrm{n}=8)$ & MIT $(n=4)$ & $\operatorname{HIT}(n=3)$ & $p$-Value & $\mathrm{PT}(\mathrm{n}=15)$ & $\begin{array}{c}p \text {-Value } \\
\text { SC vs. PT }\end{array}$ \\
\hline Mean weight \pm SD prior to $\mathrm{MNU}(\mathrm{g})$ & $105.67 \pm 11.66$ & $111.25 \pm 24.16$ & $107.50 \pm 37.75$ & $97.67 \pm 19.50$ & 0.81 & $107.53 \pm 26.08$ & 0.81 \\
\hline Mean dose \pm SD of $\mathrm{MNU}(\mathrm{ml} / \mathrm{kg})$ & $1.92 \pm 0.22$ & $2.05 \pm 0.46$ & $2.00 \pm 0.58$ & $1.77 \pm 0.38$ & 0.77 & $1.98 \pm 0.46$ & 0.80 \\
\hline Mean weight \pm SD at necropsy $(\mathrm{g})$ & $288.67 \pm 17.83$ & $286.25 \pm 18.47$ & $297.50 \pm 25.98$ & $297.33 \pm 21.20$ & 0.73 & $291.47 \pm 20.31$ & 0.69 \\
\hline
\end{tabular}

PT: Training rats, LIT: low-intensity training, MIT: moderate-intensity training, HIT: high-intensity training, SC: sedentary control, SD: standard deviation.

to all cancer cells evaluated under $\times 400$ magnification. The final score was an average of three measurements from the fields of the most intense expression ('hot spots'), given as a percentage.

Determination of plasma hormone levels. 17 $\beta$-Estradiol and progesterone were determined by enzyme-linked fluorescent assay (ELFA; BioMerieux, Marcy-L'etoile, France), according to the manufacturer's recommendations. All the steps of the study were performed automatically by a VIDAS immunoanalyzer (BioMerieux), including automated calculation of results in relation to the programmed calibration curve.

Statistical analysis. The Shapiro-Wilk test was used to evaluate the normality assumption of the examined groups, and the Levene's test for the homogeneity of variance. The Mann-Whitney and KruskalWallis tests were utilized to compare differences between expression and levels of examined markers. Additionally, the Spearman correlation test was used to verify existing correlations. All the statistical analyses were performed using Prism 5.0 (GraphPad, La Jolla, CA, USA) and Statistica 10 (Statsoft, Cracow, Poland). The results were considered statistically significant when $p<0.05$.

\section{Results}

The statistical analysis was performed only on cases with induced tumors: nine from the SC group and 15 from the PT groups, in regard to the observed color reactions (Figure 1). The examined rats did not differ significantly in terms of their body weight, amount of administered MNU (Table II). Neither significant differences in tumor volume nor proliferation in PT groups were demonstrated (Figure 2A-D). However, a moderate negative correlation between the number of tumors and intensity of PT was observed $(\mathrm{r}=-0.47, p=0.02$; Figure $3 \mathrm{~A})$. Moreover, a positive correlation between volume and number $(\mathrm{r}=0.68, p=0.02$; Figure $3 \mathrm{~B}$ ), as well volume and proliferative rate of induced tumors was found ( $\mathrm{r}=0.60, p=0.001$; Figure $3 \mathrm{C}$ ).

Apoptosis was significantly stronger in the PT groups $v s$. the SC group, however, an increasing trend was only apparent for LIT and MIT groups (Figure 2E, F). Increased apoptosis positively correlated with PT intensity level ( $\mathrm{r}=0.47, p=0.02$; Figure $3 \mathrm{E})$.

No significant differences in plasma level of estradiol nor tissue expression of ER $\alpha$ in animals from PT and SC groups were disclosed (Figure 4). In comparison of plasma level of progesterone and tissue expression of PR, the only statistically significant difference was a higher progesterone level in PT groups vs. the SC group (Figure 5).

The expression of ER $\alpha$ and PR in tumor cells positively correlated with the level of apoptosis $(r=0.43, p=0.04$ and $\mathrm{r}=0.50, p=0.01$, respectively; Figure $3 \mathrm{~F}, \mathrm{G})$. Moreover, moderate correlations between expressions of ER $\alpha$ vs. Ki-67 $(\mathrm{r}=0.46, p=0.02$; Figure $3 \mathrm{H})$ and PR vs. tumor volume $(\mathrm{r}=0.50, p=0.01$; Figure 3D) were found.

\section{Discussion}

The epidemiological and experimental studies indicate a negative association between PT and breast cancer (24-26). An approximately $25 \%$ reduction of breast cancer risk was observed in physically-active women and related with the intensity of PT. According to many authors, moderate or intense PT has a significant impact on risk reduction (27-29). In the present study, we found concordant results, showing a significant decrease in the number of tumors in the experimental group undergoing intense PT.

It is generally accepted that female sex hormones play a role in the etiopathogenesis of breast cancer (30). Numerous studies indicate that overexposure, mainly to estrogens, can be related to increased risk of breast cancer development. In our study, differences between levels of estradiol in PT and SC rats were insignificant. Similar observations were disclosed by others $(25,26,31)$, whereas Erich et al. (32) and PellerinMassocotte et al. were explaining that rodents require high intensity PT to induce hormonal changes, especially related to sex hormones (33). Contrary to the general assumption that estrogen level decreases under the influence of PT, there is evidence of a significant increase of $17-\beta$ estradiol in rats undergoing long-term PT, most of all obtained by FaustinoRocha et al. in the longest exercise training protocol (35week) on mammary tumorigenesis ever performed (34).

In regard to expression of ER $\alpha$ in PT rats, results are highly contradictory. Our analysis, similarly to that of Alvarado et al., revealed no statistically significant association (35). However, Wang et al. demonstrated a reduction in ER $\alpha$ expression in 100-day-old rats undergoing PT at the early stage of life, simultaneously 

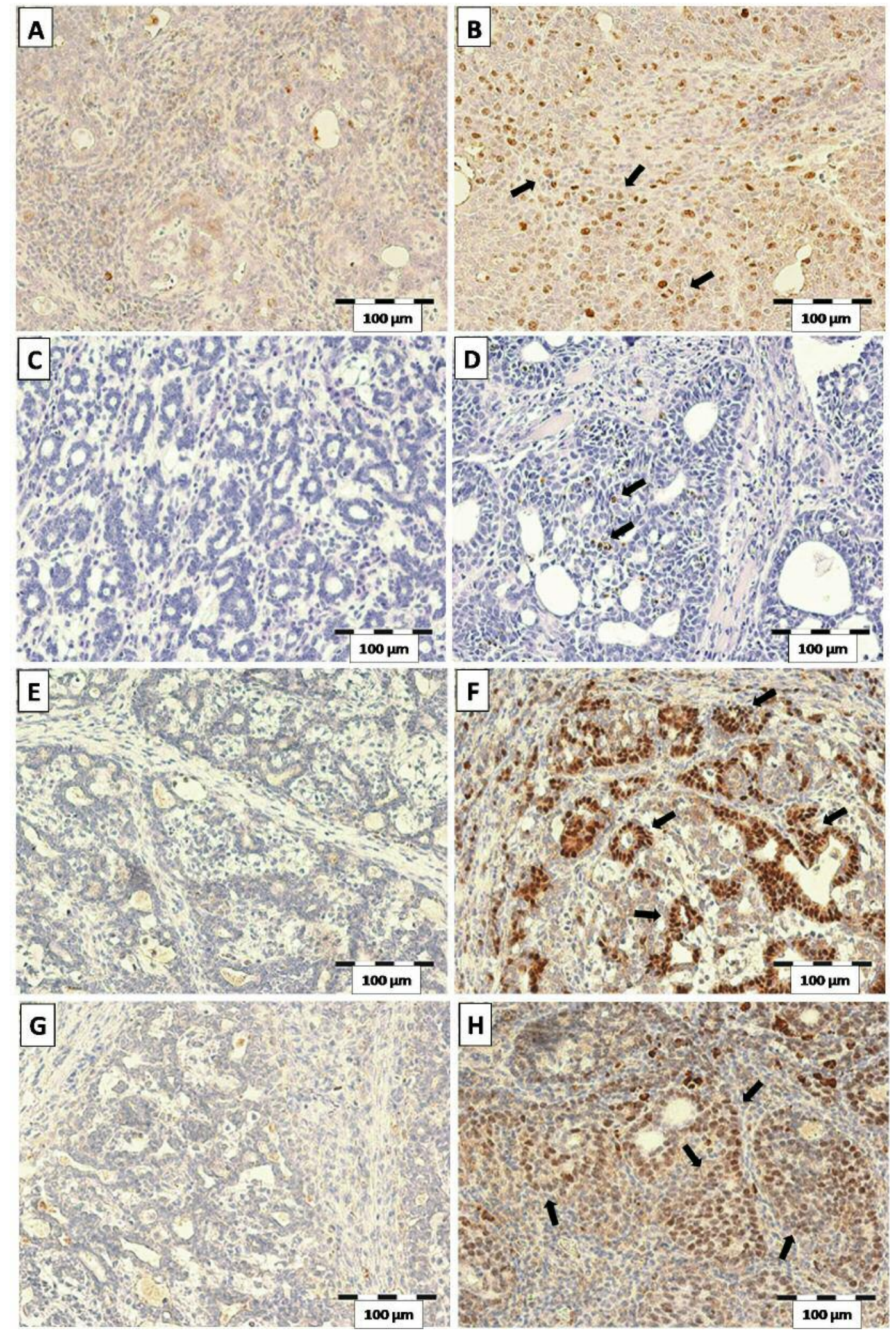

Figure 1. Immunohistochemical expression of Ki-67 proliferation antigen $(A, B)$, apoptosis detected by terminal deoxynucleotidyl transferase dUTP nick-end labeling method $(C, D)$, immunohistochemical expression of estrogen receptor $\alpha(E, F)$ and progesterone receptor $(G, H)$ in tumor cells of $N$-methyl-N-nitrosourea-induced tumors in rats. A, $C, E, G$-Absent reaction; $B, D, F, H$-nuclear reaction (arrows). 

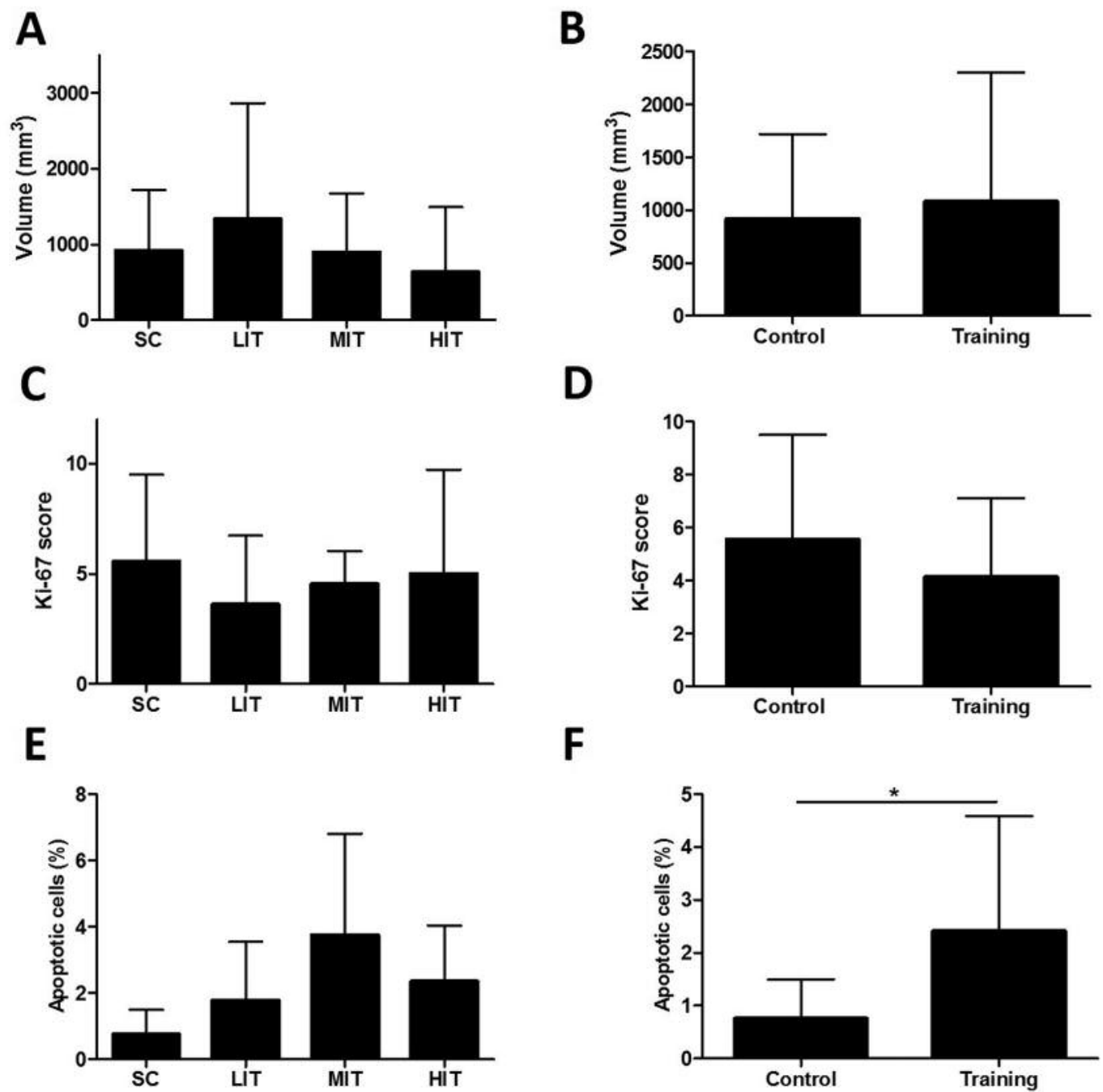

$\mathbf{F}$

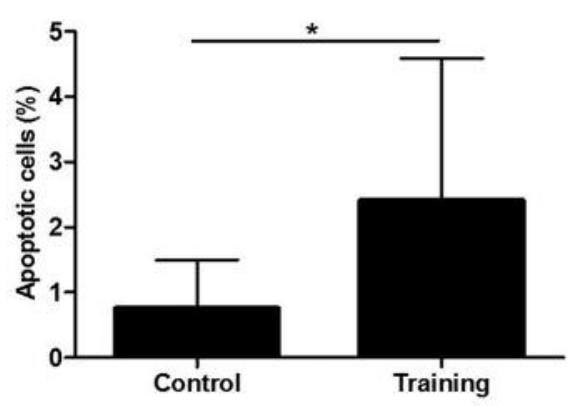

Figure 2. Comparison of tumor volume $(A, B)$, expression of Ki-67 antigen $(C, D)$, and percent of apoptotic cells $(E, F)$ between training groups and sedentary control (SC) group. LIT: Low-, MIT: moderate-; HIT: high-intensity training. Data are means \pm standard deviation. *Significantly different at $p<0.05$.

indicating a reduction in proliferation (36). In contrast, Faustino-Rocha et al. demonstrated increased ER $\alpha$ expression in MNU-induced mammary tumors in female rats undergoing PT (34). In addition, we demonstrated a moderate correlation of increased ER $\alpha$ expression in tumor cells with their proliferation and with apoptosis. Induction of proliferation in both normal and neoplastic cells of mammary gland is primarily due to the effect of estradiol on ER $\alpha$ (37). Song et al. (38) and Lewis et al. (39) demonstrated the opposite relationship, i.e. proapoptotic effect of estradiol. Nevertheless, Teixier et al. observed increased ER expression to be associated with increased apoptosis and reduced proliferation (31), with which our results are partly consistent with.

The second most important sex hormone with a significant role in breast cancer tumorigenesis is progesterone. It inhibits cell proliferation, as well as suspected capable of inducing apoptosis (40). The proapoptotic action of progesterone in the mammary gland was confirmed by Chen et al. (41) and Gompel et al. (42).

In our study, a significantly higher progesterone level was observed in PT rats, which is concordant with the results of others $(26,43)$. Thompson et al. reported that a higher level of progesterone was significantly related to a lower incidence of cancer in experimental animals (26). Additionally, we demonstrated a positive correlation between PR expression and the number of apoptotic cells, which may be confirmation of the observations of Chen et al. (41) and Gompel et al. (42). Moreover, Wiebe et al. indicated the possibility of different metabolic profiles for progesterone, which inter alia may be observed in healthy and diseased mammary glands. Both the possibility of stimulation of cell 
A

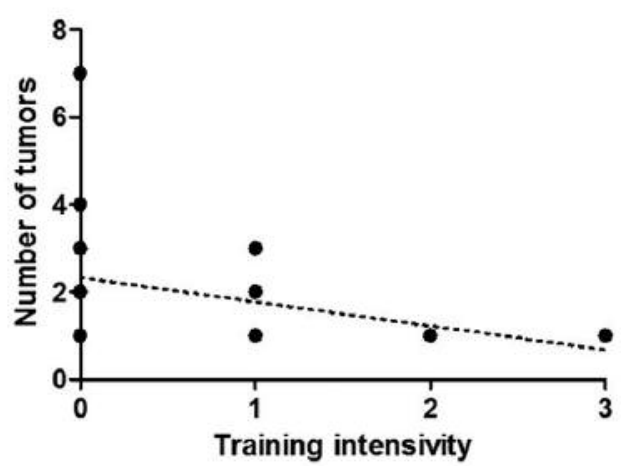

C

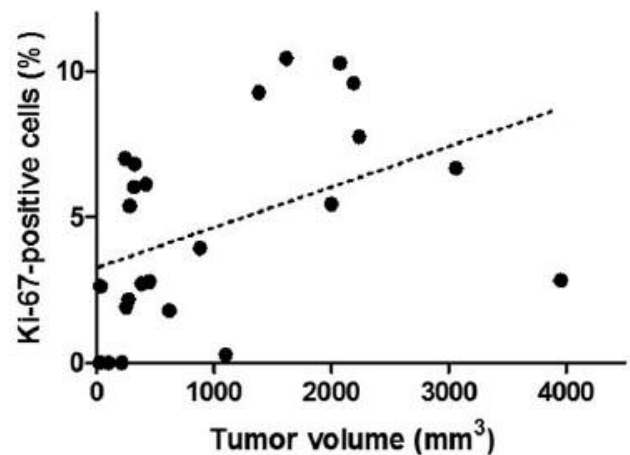

E

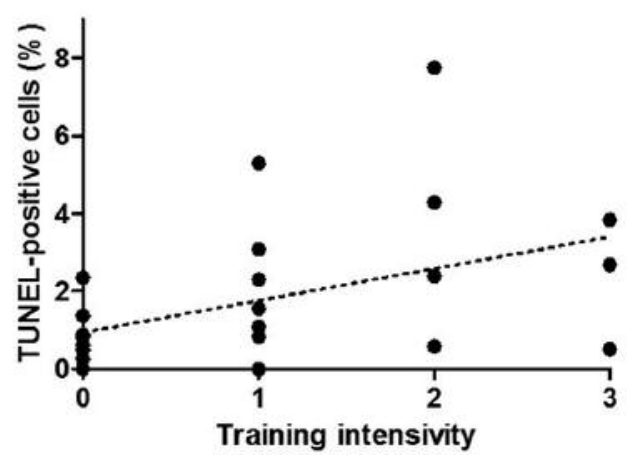

$\mathbf{G}$

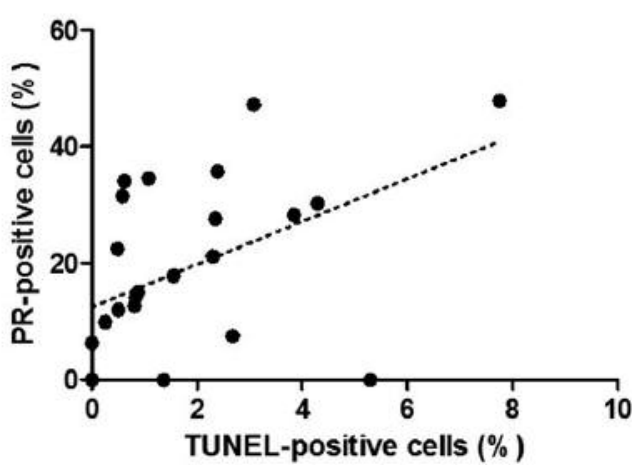

B

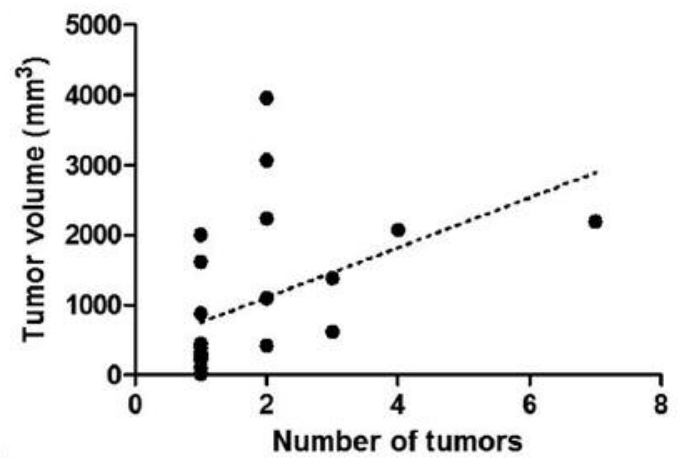

D

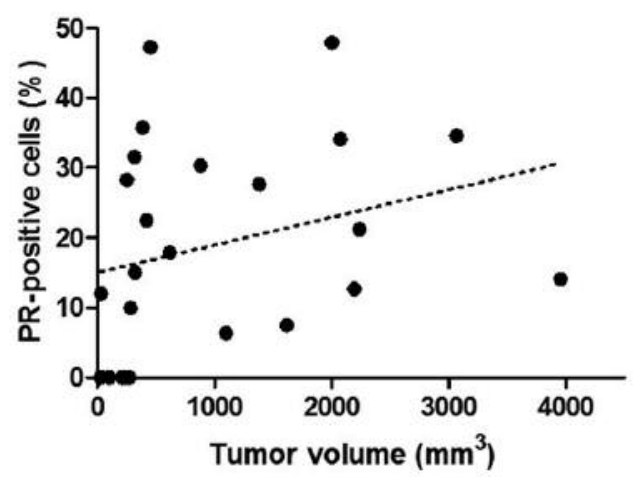

$\mathbf{F}$

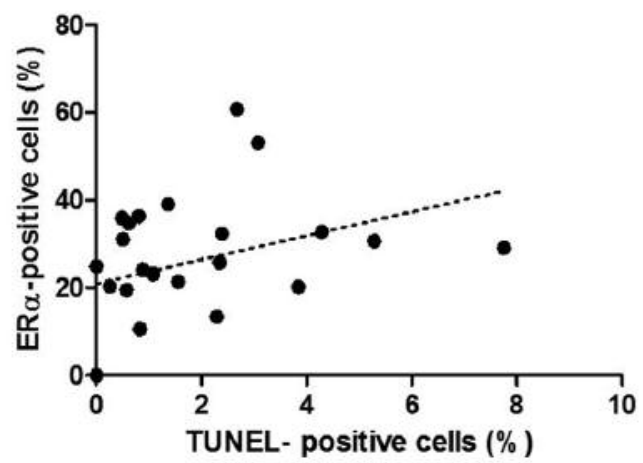

H

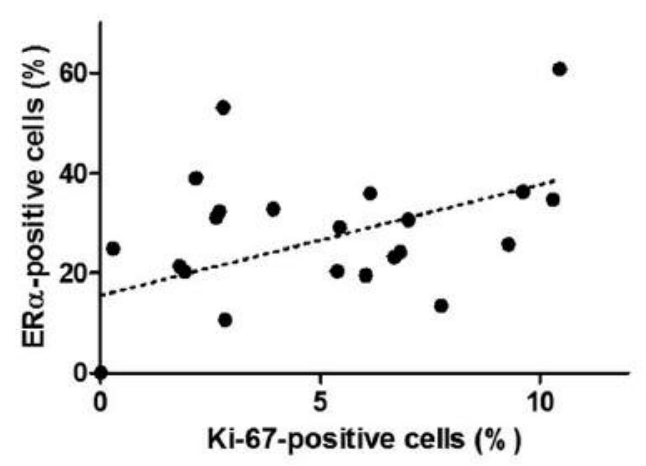

Figure 3. Spearman rank correlation analysis for the number of tumors induced and the intensity level of physical training $(A ; r=-0.47, p=0.02)$, for the number of induced tumors and their volume $(B ; r=0.68, p=0.02)$, for tumor volumes and expression of Ki-67 (C; $r=0.60, p=0.001)$, for tumor volumes and progesterone receptor $(P R)$ expression $(D ; r=0.50, p=0.01)$, for training intensity and the number of apoptotic cells $(E ; r=0.47$, $p=0.02)$, for apoptotic cells and estrogen receptor $(E R \alpha)$ expression $(F ; r=0.43, p=0.04)$, for the number of apoptotic cells and PR expression $(G$; $r=0.50, p=0.01)$, for the expressions of Ki-67 and ER $(H ; r=0.46, p=0.02)$. TUNEL: Terminal deoxynucleotidyl transferase dUTP nick-end labeling. 
A

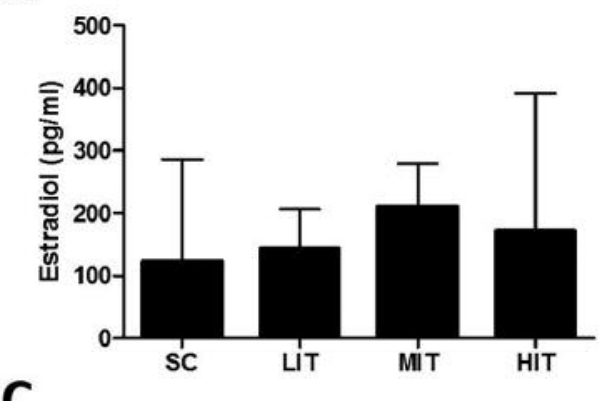

C

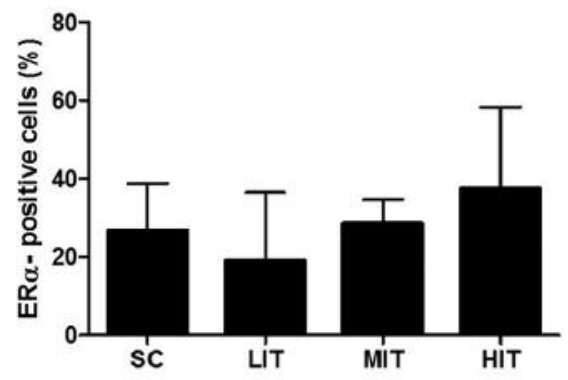

B

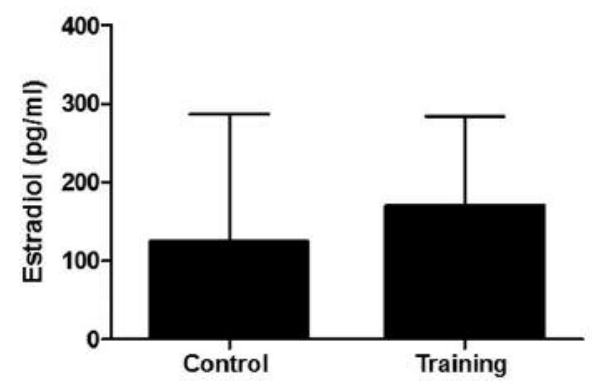

D

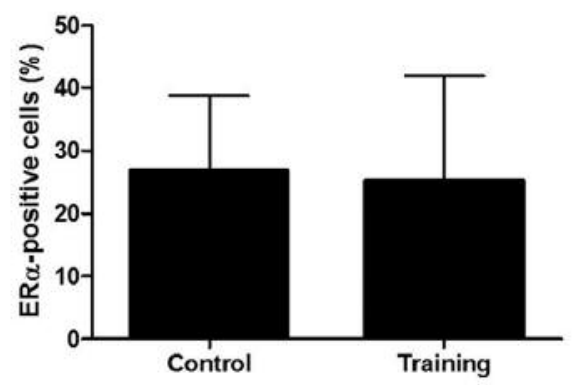

Figure 4. Comparison of plasma level of estradiol $(A, B)$ and expression of estradiol receptor $(E R)-\alpha(C, D)$ between training groups and sedentary control (SC) group. LIT: Low-, MIT: moderate-; HIT: high-intensity training. Data are means \pm standard deviation.

A
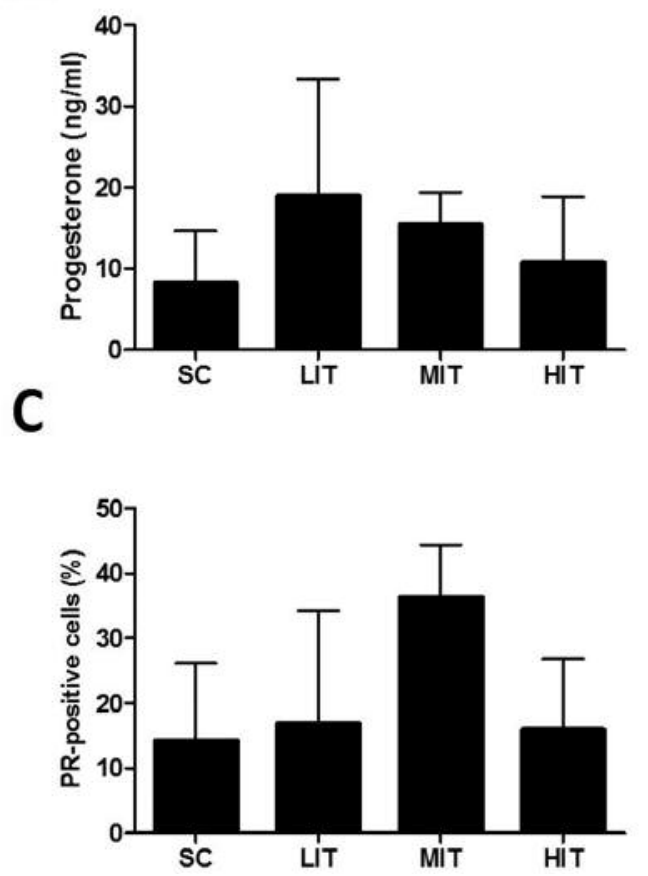

B

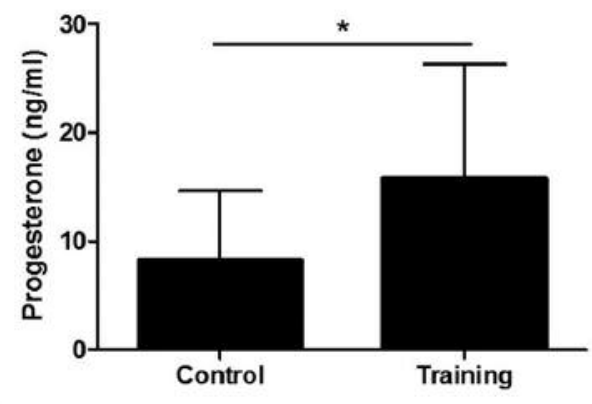

D

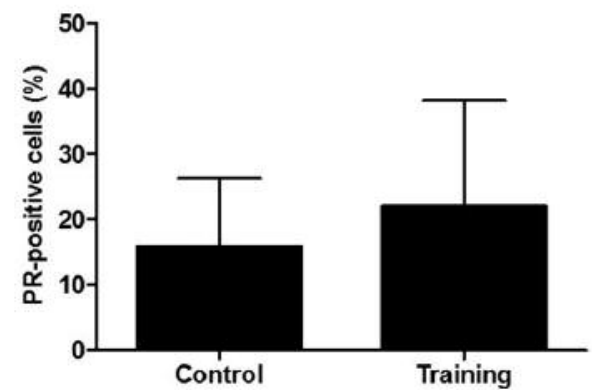

Figure 5. Comparison of plasma level of progesterone $(A, B)$ and expression of progesterone receptor $(P R)(C, D)$ between training groups and sedentary control (SC) group. LIT: Low-, MIT: moderate-; HIT: high-intensity training. Data are means \pm standard deviation. *Significantly different at $p<0.05$. 
proliferation and the antimitotic effect of increasing cell apoptosis were demonstrated (9). Perhaps PT may influence progesterone metabolism, thus having a different effect on tumor cells. Steindorf et al. also suggest that moderate and high physical activity is associated with modestly reduced breast cancer risk (44).

Based on the obtained study results, PT seems to have a greater effect on progesterone metabolism without significantly affecting the estradiol level. In turn, progesterone induced by PT may be significant in inhibiting the development of mammary gland cancer (45). In addition, we observed increased tumor cell apoptosis in groups undergoing PT and its positive correlation with the intensity of PT, which suggests a protective role of PT in carcinogenesis.

In conclusion, properly-tailored PT may have a suppressive effect on breast cancer development in a mechanism controlled mostly by progesterone metabolism.

\section{Acknowledgements}

The Authors thank Mrs. Bozena Przygodzka, Mrs. Agnieszka Baranska and Mrs. Elzbieta Polejko for their technical assistance. This work was funded by the grant of the Polish Ministry of Science N N404088240 "Impact of Physical Training on the Carcinogenesis and Progression of Rat Mammary Glands".

\section{References}

1 Siegiel R, Miller KD and Jemal A: Cancer Statistics, 2017. CA Cancer J Clin 67: 7-30, 2017.

2 Kuhl H and Schneider HP: Progesterone - promoter or inhibitor of breast cancer. Climacteric 16: 54s-68s, 2013.

3 Gonçalves AK, Dantas Florencio GL, Maisonnette de Atayde Silva MJ, Cobucci RN, Giraldo PC and Cote NM: Effects of physical activity on breast cancer prevention: a systematic review. J Phys Act Health 11: 445-454, 2014.

4 Person I: Estrogens in the causation of breast, endometrial and ovarian cancers - evidence and hypotheses from epidemiological findings. J Steroid Biochem Mol Biol 74: 357-364, 2000.

5 Friedenreich CM: Physical activity and breast cancer: review of the epidemiologic evidence and biologic mechanisms. Recent Results Cancer Res 188: 125-139, 2011.

6 Coyle Y: Physical activity as a negative modulator of estrogeninduced breast cancer. Cancer Causes Control 19: 1021-1029, 2008.

7 Liu C, Zhang $\mathrm{CH}$, Shuang $\mathrm{CCH}$, Lu CY, Jin CF, Huimian $\mathrm{C}$ and $\mathrm{Xu}$ Ping L: Alternations of ER, PR, HER-2/neu, and P53 protein expression in ductal breast carcinomas and clinical implications. Med Oncol 27: 747-752, 2010.

8 Lester SC and Hicks D: Diagnostic Pathology: Breast. Diagnostic Pathology Series. Elsevier. Philadelphia, p. 431, 2016.

9 Wiebe J: Progesterone metabolites in breast cancer. Endocr Relat Cancer 13: 717-738, 2006.

10 Ennour-Idrissi K, Maunsell E and Diorio C: Effect of physical activity on sex hormones in women: a systematic review and metaanalysis of randomized controlled trials. Breast Cancer Res 17: 139, 2015.
11 Verkasalo PK, Thomas HV, Appleby PN, Davey GK and Key TJ: Circulating levels of sex hormones and their relation to risk factors for breast cancer: a cross-sectional study in 1092 pre- and postmenopausal women (United Kingdom). Cancer Causes Control 12: 47-59, 2001.

12 McTiernan A, Tworoger SS, Ulrich CM, Yasui Y, Irwin ML, Rajan KB, Sorensen B, Rudolph RE, Bowen D, Stanczyk FZ, Potter JD and Schwartz RS: Effect of exercise on serum estrogens in postmenopausal women: a 12-month randomized clinical trial. Cancer Res 64: 2923-2928, 2004.

13 Atkinson C, Lampe JW, Tworoger SS, Ulrich CM, Bowen D, Irwin ML, Schwartz RS, Rajan BK, Yasui Y, Potter JD and McTiernan A: Effects of a moderate intensity exercise intervention on estrogen metabolism in postmenopausal women. Cancer Epidemiol Biomarkers Prev 13: 868-874, 2004.

14 Matthews CE, Fortner RT, Xu X, Hankinson SE, Eliassen AH and Ziegler RG: Association between physical activity and urinary estrogens and estrogen metabolites in premenopausal women. J Clin Endocrinol Metab 97: 3724-3733, 2012.

15 Bardia A, Hartmann LC, Vachon CM, Vierkant R, Wang A, Olson J, Sellers $\mathrm{T}$ and Cerhan J: Recreational physical activity and risk of postmenopausal breast cancer based on hormone receptor status. Arch Intern Med 166: 2478-2483, 2006.

16 Schmidt ME, Steindorf K, Mutschelknauss E, Slanger T, Kropp S, Obi N, Flesch-Janys D and Chang-Claude J: Physical activity and postmenopausal breast cancer: Effect modification by breast cancer subtypes and effective periods in life. Cancer Epidemiol Biomark Prev 17: 3402-3410, 2008.

17 Peters TM, Moore SC, Gierach GL, Wareham NJ, Ekelund U, Hollenbeck AR, Schatzkin A and Leitzmann MF: Intensity and timing of physical activity in relation to postmenopausal breast cancer risk: The prospective NIH-AARP Diet and Health Study. BMC Cancer 9: 349, 2009.

18 Cardiff RD and Wellings SR: The comparative pathology of human and mouse mammary glands. J Mammary Gland Biol Neoplasia 4: 105-122, 1999.

19 Ko EY, Lee SH, Kim HH, Kim SM, Shin MJ, Kim N and Gong G: Evaluation of tumor angiogenesis with a second-generation US contrast medium in a rat breast tumor model. Korean $\mathbf{J}$ Radiol 9: 243-249, 2008.

20 Pula B, Malicka I, Pawlowska K, Paslawska U, Cegielski M, Podhorska-Okolow $\mathrm{M}$, Dziegiel $\mathrm{P}$ and Wozniewski $\mathrm{M}$ : Immunohistochemical characterization of $N$-methyl- $N$-nitrosoureainduced mammary tumours of Sprague-Dawley rats. In Vivo 27: 793-802, 2013.

21 Malicka I, Siewierska K, Pula B, Kobierzycki C, Haus D, Cegielski M, Dziegiel P, Podhorska-Okolow M and Wozniewski $\mathrm{M}$ : The effect of physical training on the $N$-methyl- $N$-nitrosourea induced mammary carcinogenesis of Sprague-Dawley Rats. Exp Biol Med 240: 1408-1415, 2015.

22 Podhorska-Okołów M, Krajewska B, Carraro U and Zabel M: Apoptosis in mouse skeletal muscles after physical exercise. Folia Histochem Cytobiol 37: 127-128, 1999.

23 Russo J and Russo IH: Atlas and histologic classification of tumors of the rat mammary gland. J Mammary Gland Biol Neoplasia 5: 187-200, 2000.

24 Friedenreich CM, Thune I, Brinton LA and Albanes D: Epidemiologic issues related to the association between physical activity and breast cancer. Cancer 83: 600s-610s, 1998. 
25 Westerlind KC, McCarty HL, Gibson KJ and Strange R: Effect of exercise on the rat mammary gland: implications for carcinogenesis. Acta Physiol Scand 175: 147-156, 2002.

26 Thompson HJ, Wolfe P, McTiernan A, Jiang and Zhu Z: Wheel running induced changes in plasma biomarkers and the carcinogenic response in the 1-methyl 1-nitorosourea induced rat model for breast cancer. Cancer Prev Res 3: 1484-1492, 2010.

27 Westerlind KC, McCarty HL, Schultheiss PC, Story R, Reed $\mathrm{AH}$, Baier ML and Strange R: Moderate exercise training slows mammary tumour growth in adolescent rats. Eur J Cancer Prev 12: 281-287, 2003

28 Bacurau AV, Belmonte MA, Navarro F, Moraes MR, Pontes FL Jr., Pesquero JL, Araújo RC and Bacurau RF: Effect of a highintensity exercise training on the metabolism and function of macrophages and lymphocytes of walker 256 tumor bearing rats. Exp Biol Med (Maywood) 232: 1289-1299, 2007.

29 Zhu Z, Jiang W, McGinley JN and Thompson HJ: Energetics and mammary carcinogenesis: effects of moderate-intensity running and energy intake on cellular processes and molecular mechanisms in rats. J Appl Physiol 106: 911-918, 2009.

30 Campognoli C, Clavel-Chapelon F, Kaaks R, Peris C and Berrino F: Progestins and progesterone in hormone replacement therapy and the risk of breast cancer. J Steroid Biochem Mol Biol 96: 95-108, 2005.

31 Teixeira GR, Fávaro WJ, Pinheiro PF, Chuffa LG, Amorim JP, Mendes LO, Fioruci BA, Oba E, Martins OA, Martinez M and Martinez FE: Physical exercise on the rat ventral prostate: steroid hormone receptors, apoptosis and cell proliferation. Scand J Med Sci Sports 22: 86-92, 2012.

32 Erich WBM, Peltenburg AL and Minkhorst J: The influence of physical exercise on growth and sexual maturation in young female rats. Growth 49: 131-140, 1985.

33 Pellerin-Massocotte J, Brisson GR, St-Pierre C, Rioux P and Rajotte D: Effect of exercise on the onset of puberty, gonadotropins, and ovarian inhibin. J Appl Physiol 63: 1165-1173, 1987.

34 Faustino-Rocha AI, Gama A, Oliveira PA, Alvarado A, Neuparth MJ, Ferreira R and Ginja M: Effects of lifelong exercise training on mammary tumorigenesis induced by MNU in female Sprague-Dawley rats. Clin Exp Med 17: 151-160, 2017.

35 Alvarado A, Faustino-Rocha AI, Ferreira R, Mendes R, Duarte JA, Pires MJ, Colaço B and Oliveira PA: Prognostic factors in an exercised model of chemically-induced mammary cancer. Anticancer Res 36: 2181-2188, 2016.

36 Wang M, Yu B, Westerlind K, Strange R, Khan G, Patil D, Boeneman $\mathrm{K}$ and Hilakivi-Clarke L: Prepubertal physical activity up-regulates estrogen receptor beta, BRCA1 and p53 mRNA expression in the rat mammary gland. Breast Cancer Res Treat 115: 213-220, 2009
37 Coyle Y: Physical activity as a negative modulator of estrogeninduced breast cancer. Cancer Causes Control 19: 1021-1029, 2008.

38 Song RXD, Mor G, Naftolin F, McPherson RA, Song J, Zhang Z, Yue W, Wang J and Santen RJ: Effect of long-term estrogen deprivation on apoptotic responses of breast cancer cells to $17 \mathrm{~b}-$ estradiol. J Natl Cancer Inst 93: 1714-1723, 2001.

39 Lewis JS, Meeke K, Osipo C, Ross EA, Kidawi N, Li T, Bell E, Chandel NS and Jordan VC: Intrinsic mechanism of estradiolinduced apoptosis in breast cancer cells resistant to estrogen deprivation. J Natl Cancer Inst 97: 1746-1759, 2005.

40 Formby B and Wiley TS: Progesterone inhibits growth and induces apoptosis in breast cancer cell: inverse effects on Bcl-2 and p53. Ann Clin Lab Sci 28: 360-369, 1998.

41 Chen FP, Chien MH, Chen HY and Ng YT: Effects of different progestogens on human breast tumor cell growth. Climacteric 14: 345-351, 2011.

42 Gompel A, Somaï S, Chaouat M, Kazem A, Kloosterboer HJ, Beusman I, Forgez P, Mimoun M and Rostène W: Hormonal regulation of apoptosis in breast cells and tissues. Steroids 65: 593-598, 2000

43 Zhu Z, Jiang W, Zacher JH, Neil ES, McGinley JN and Thompson HJ: Effects of energy restriction and wheel running on mammary carcinogenesis and host systemic factors in a rat model. Cancer Prev Res 5: 414-422, 2012.

44 Steindorf K, Ritte R, Eomois PP et al: Physical activity and risk of breast cancer overall and by hormone receptor status: The European Prospective Investigation into Cancer and Nutrition Int J Cancer 132: 1667-1678, 2013.

45 Micheli A, Muti P, Secreto G, Krogh V, Meneghini E, Venturelli E, Sieri S, Pala V and Berrino F: Endogenous sex hormones and subsequent breast cancer in pre-menopausal women. Int $\mathrm{J}$ Cancer 112: 312-318, 2004.
Received May 4, 2017

Revised May 19, 2017

Accepted May 23, 2017 